Entry

\title{
Tsunami Alert Efficiency
}

\author{
Amir Yahav $1, *,+(\mathbb{D})$ and Amos Salamon $2, *,+\mathbb{D}$
}

1 National Steering Committee for Earthquake Preparedness, 6th Habaal Shem-tov, Lod 7128906, Israel

2 Geological Survey of Israel, 32 Yeshayhu Leibowitz Street, Jerusalem 9692100, Israel

* Correspondence: av_y@hotmail.com (A.Y.); salamon@gsi.gov.il (A.S.); Tel.: +972-5062-99024 (A.Y.); +972-5062-35281 (A.S.)

+ These authors contributed equally to this work.

Citation: Yahav, A.; Salamon, A. Tsunami Alert Efficiency. Encyclopedia 2022, 2, 383-399. https://doi.org/ 10.3390/encyclopedia2010023

Academic Editors: Raffaele Barretta, Ramesh Agarwal, Krzysztof Kamil Żur and Giuseppe Ruta

Received: 29 October 2021

Accepted: 26 January 2022

Published: 1 February 2022

Publisher's Note: MDPI stays neutral with regard to jurisdictional claims in published maps and institutional affiliations.

Copyright: (C) 2022 by the authors. Licensee MDPI, Basel, Switzerland. This article is an open access article distributed under the terms and conditions of the Creative Commons Attribution (CC BY) license (https:// creativecommons.org/licenses/by/ $4.0 /)$.
Definition: "Tsunami Alert Efficiency" is the rapid, accurate and reliable conduct of tsunami warning messaging, from the detection of potential tsunamigenic earthquakes to dissemination to all people under threat, and the successful survival of every person at risk on the basis of prior awareness and preparedness.

Keywords: decision matrix; tsunami alert; tsunami awareness; tsunami efficiency; tsunami hazard; tsunami messages; tsunami preparedness; tsunami ready; tsunami risk; tsunami warning

\section{Introduction}

Lessons learnt from recent disastrous tsunamis point towards significant gaps between the science behind tsunami warning and the practice of saving lives and minimizing risk [1-3]. Most notable was the identification of the 26 December 2004 Sumatra Mw 9.1 tsunamigenic earthquake in near real time, and due to the lack of communication means and unpreparedness there was no way to alert the circum-Indian Ocean inhabitants. Consequently, a quarter of million people lost their lives [4]. This catastrophe was considered an "eye-opener" [5], showing that, clearly, although tsunamis cannot be prevented, the massive loss of lives was avoidable and the scope of damages was mitigable.

About 7 years later, on 11 March 2011 the world faced another deadly tsunami event caused by the Mw 9.0 tsunamigenic Tohoku-Oki earthquake east of Honshu Island in Japan. This calamity cost the lives of about 18,500 people [6].

"Recognizing the increasing impact of disasters and their complexity in many parts of the world" [7], the third UN World Conference on Disaster Risk Reduction met on 18 March 2015 in Sendai, Japan, and decided to adopt the "Sendai Framework for Disaster Risk Reduction 2015-2030" [8]. The Sendai Framework presented four priorities for action: (1) understanding disaster risk; (2) strengthening disaster risk governance to manage disaster risk; (3) investing in disaster risk reduction for resilience; and (4) enhancing disaster preparedness for effective responses and to "Build Back Better" in recovery, rehabilitation and reconstruction. In addition, the Sendai declaration urged stakeholders to take actions in order to "... enhance our efforts to strengthen disaster risk reduction to reduce disaster losses of lives and assets worldwide" [7].

The disasters motivated the Intergovernmental Oceanographic Commission (IOC) of United Nations Educational, Scientific and Cultural Organization (UNESCO) to establish Intergovernmental Coordination Groups (ICGs) for tsunami early warning and mitigation systems (TWS) in the Indian Ocean [9]; the north-eastern Atlantic, Mediterranean and Connected Seas (NEAMTWS) [10]; and the Caribbean (ICG/CARIBE EWS) [11]; in addition to the already existing Pacific Tsunami Warning Center (PTWC) [12] in Hawaii and the Japanese Meteorological Agency (JMA) [13].

In fact, ICG/PTWC is a new name for the existing International Coordination Group for the Tsunami Warning System in the Pacific (ICG/ITSU), that was established in 1965 
after several decades of deadly tsunami catastrophes in the Pacific Ocean by a joint international effort under the umbrella of the IOC/UNESCO, which was thus the pioneer of the ICG/TWC groups [14]. Nowadays, “ ... the (PTWC) provides warnings of tsunamis to the public and to organizations responsible for public safety in coastal areas of Hawai'i (since 1949), the Pacific Ocean (since 1965), the Indian Ocean (since 2005), and the Caribbean Sea (since 2006)." [15].

Thus, the space between tsunami generation at the one end, and the civil and public response at the other end, is nowadays covered by a systematic architecture of organizations that transfer tsunami alerts from end to end rapidly, accurately and reliably, on the basis of systematic Standard Operational Procedures (SOP) [16]. Yet the array of various bodies may complicate and delay the timely arrival of warning messages up to the very last threatened citizen, and therefore the alerting process should be conducted efficiently [17]. Orderly SOPs are of course required, and usually they are taken care of within the organizations [18], yet there is a need for efficient communication, because the chain is no stronger than its weakest link. Moreover, receiving the warning messages on time does not assure successful lifesaving conduct. Appropriate awareness [19] and preparedness [20] are necessary requirements for effective lifesaving behavior and must be integrated in the alerting process.

Here we describe the leading concepts behind the tsunami alerting process, emphasizing the importance of the corresponding awareness and preparedness, and discuss the difficulties and uncertainties that may downgrade its efficiency, because the effective conduct of the alerting process is the ultimate key to saving lives under threat. We aim not to rephrase existing SOPs or user guides, but bring to mind some thoughts on making tsunami alerts more efficient and effective.

\section{The Alerting Process-End to End Organizing Architecture}

Tsunami alert efficiency is defined here as the rapid, accurate and reliable conduct of tsunami warning messaging, from the detection of a potential tsunamigenic earthquake to the dissemination to all people under threat, and to the successful survival of every person at risk on the basis of prior tsunami readiness, awareness and preparedness. Accordingly, successful lifesaving shows good conduct and high alert efficiency, while a loss of lives reflects a failure of conduct and poor efficiency. The key to success or reasons for failure originate in the alerting process, and thus we center the following overview on this issue.

The alerting process is performed through several channels in an end-to-end (ETE) architecture (Figure 1) which is a chain that aims to transmit reliable data and tsunami warnings, urgently and fast, with the ultimate goal of saving the lives of people at risk. Here we follow the UNESCO/IOC [18] recommendations on NEAMTWS ETE architecture, and elaborate on:

- The ETE architecture;

- The elements that compose the ETE architecture;

- The regional, national and local domains under which the chain operates;

- The communication that bonds the elements;

- The last mile: lifesaving and self-evacuation;

- Factors behind the alert-awareness and preparedness;

- The fact that not all tsunamis are equal-regional, local and spontaneous events. 


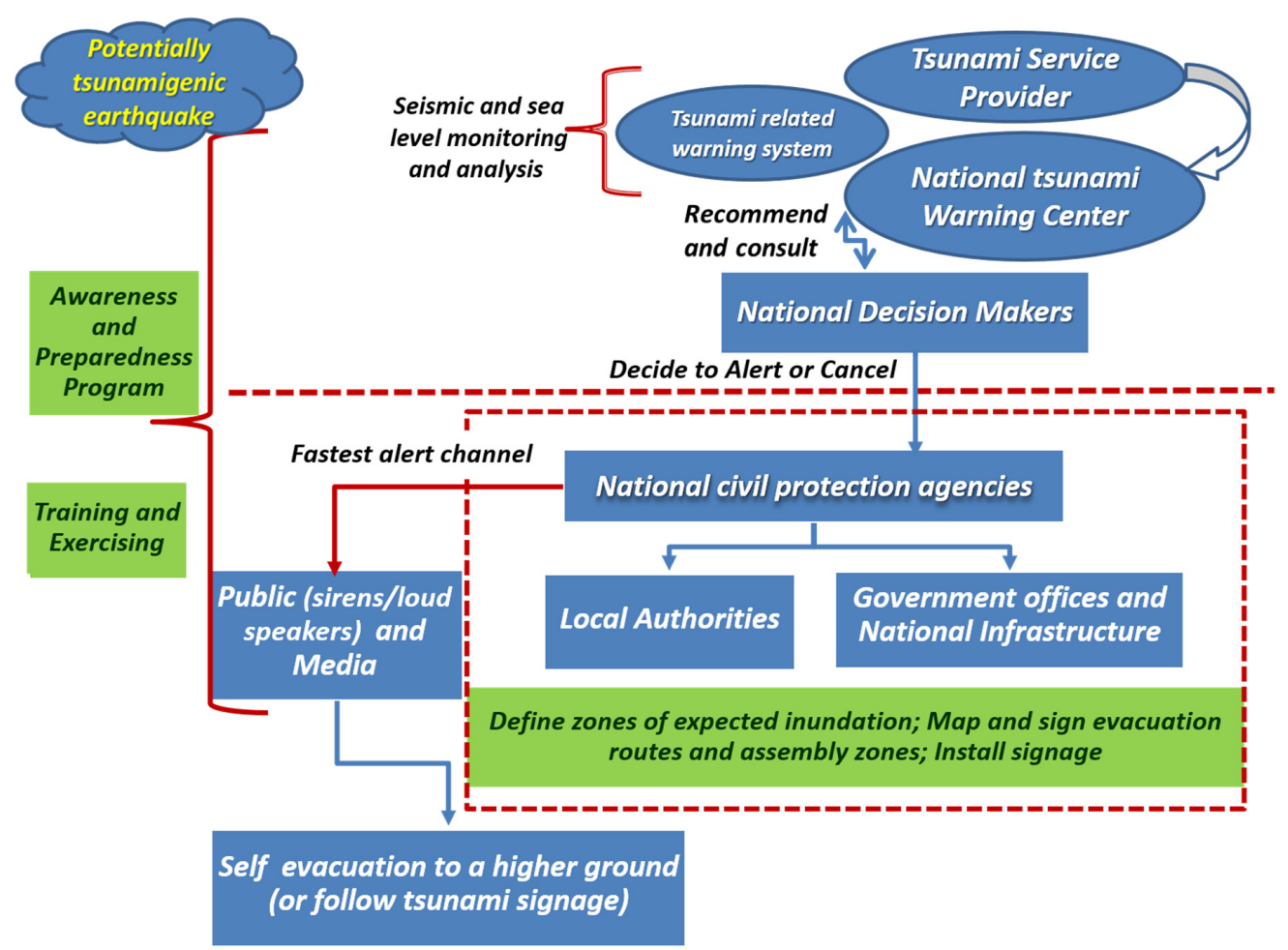

Figure 1. Generic end-to-end organizing architecture and the expected real-time flow of tsunami alerting and information.

The rationale is that proper application of all the components of the ETE architecture is the key to efficient tsunami alerting. "Efficiency" in this context means a reliable, accurate, fast and successful reach of the warning messages, from potential tsunami generation up to the last citizen, with an emphasis on the clear understanding and proper lifesaving behavior of the very last recipients.

We do not intend to present tsunami alert SOPs, detailed user guides or manuals; those can be found elsewhere [21]. Rather, we focus on the ideas and concepts behind the ETE architecture, with the understanding that the efficient conduct of the alerting process in which awareness and preparedness are integral parts, is the key to successful lifesaving. We further describe several examples experienced by Israel from its perspective as a member state of the ICG/NEAMTWS, and also mention other examples from elsewhere in the world.

\section{The Elements of the ETE Architecture}

The ETE architecture consists of several independent elements that all together enable the flow of information and warning messages along this chain (Figure 1). There is no restriction on the exact configuration of the elements, but they must bridge the whole ETE span, leaving no link open. Here we refer to a generic architecture, noticing that each setting is unique to its geographical, political and social environment; some elements can be merged into a single unit, while others can be sub-divided. Detailed information on contemporary tsunami early warning systems appear on the website http://www.ioctsunami.org/ (accessed on 25 January 2022) [22].

\subsection{Tsunami Service Provider (TSP)}

The first and leading element, the tsunami service provider (TSP), is a center responsible $24 / 7$ for identifying tsunami generation in the geographical area it oversees, and if needed it issues appropriate tsunami threat information [23]. TSPs should monitor, detect, collect, record, process and analyze all relevant earthquake data-mainly the epicenter, depth, magnitude and origin time - that indicate the occurrence of a potential tsunamigenic 
earthquake. If they do, the TSP calculates the estimated arrival time and severity of the threat to a predefined list of coastal forecast points, and distributes the warning messages to its list of recipients. "To respect country sovereign rights, TSPs cannot issue warnings for another country, but can of course act as the NTWC issuing warnings for its own country" [24].

In parallel, the TSPs monitor in real-time sea-level indicators such as the tide, wave heights and sea-floor pressure fluctuations, in order to verify whether a tsunami was generated or not, reevaluate the potential threat of tsunami and update the warning messages. The TSPs follow the event closely as long as required, and update the warning messages according to the level of threat until it is over. If no tsunami is observed or tsunami threat no longer exists, the TSP cancels the alert and issues a cancelation message in a prescribed format [23].

As tsunami-meter and tide gauge systems are expanded around the world [25], highly sophisticated arrays are installed near potential tsunamigenic sources in Japan [26], cheaper and easier to operate tsunami alerting devices [27] are developed and set up [28], and new techniques are introduced [29], the verification of tsunami generation becomes faster and more reliable.

The main TSP challenge is to apply raw scientific data to operational use. On the one hand, the TSP is a scientifically based research institute, while on the other hand it should work under strict and high-level operational procedures. In doing so, the TSP must cope in near real time with preliminary, partial sets of seismological and sea level data, large uncertainties originating from the monitoring systems, calculation procedures and empirical decision matrix, under time pressure, and yet still issue timely and reliable warning messages $[30,31]$. A TSP that maintains and performs successfully the SOP requirements approved by the ICG it belongs to is accredited officially.

\subsection{National Tsunami Warning Center (NTWC)}

States who do not operate TSPs are still required to evaluate and deliver tsunami threat warnings to its governed coasts. Whether such National Tsunami Warning Centers (NTWCs) manage "in-house" analysis capabilities for the independent assessment of tsunami threat, or receive ready-made tsunami warning messages from TSPs, they are responsible for verifying and issuing official alerts. Preferably, an NTWC should be a scientific unit that is able to compile a large body of information in a short time and come up with a clear decision on the level of tsunami threat to its mandated coasts [32].

The challenge NTWCs and TSPs face is to evaluate the tsunami threat on the basis of limited seismological and sea level data within a short time window, and still carry full responsibility for its administrated population at risk. The need to issue a rapid evaluation before the tsunamis hit the coasts does not allow enough time for a definite determination of tsunami generation and providing an unequivocal true and reliable alarm. Thus, at present tsunami warning is associated with large uncertainties [33], and false alarms are unavoidable. To cope with these shortcomings, warning centers adopt a probabilistic tsunami forecasting (PTF) approach in order to quantify and reduce those uncertainties in real-time [1,34]. Without explaining this to the general public, warning messages can be perceived as "cry wolf" [35], lead to warning fatigue [36], and TSPs or NTWCs may lose trust and credibility.

Furthermore, NTWCs can receive several different TSP messages at the same time and should arrive at a clear, unequivocal decision on the immediate threat posed to its controlled coasts. Usually, TSPs rely on their own data sets, computer systems, calculation programs, mathematical models, and SOPs, and thus often determine different levels of threat posed by the same event on a given forecast point. This issue is further analyzed and discussed in a case in which different tsunami messages were received at the same time, for the same event and the same coasts in Israel (Section 9 below).

Overall, TSPs and NTWCs should balance their decisions between the need to inform the public of any slight chance of a coming tsunami and avoid missed alarms, while at 
the same time maintaining the credibility and trust of the public in the reliability of the warning system.

\subsection{National Decision Makers (NDM)}

While TSPs and NTWCs are required to maintain scientific capabilities, they lack the civilian and social perspectives and experience necessary for far reaching decision-making at the national level. National decision makers (NDM) must understand and accept that the information distributed by the TSPs and NTWCs is based on preliminary scientific data associated with large uncertainties and is therefore not definite. In fact, the first issue is that tsunami alerts present the "potential threat of a not yet verified tsunami", and it is up to the NDM to decide whether to alert the country or not. Their complex, far reaching decision must consider a sequence of numerous and drastic actions that should be taken once the tsunami alert is activated, while it is not yet clear whether a tsunami is actually on its way or not: for example, the immediate evacuation of hundreds of thousands of people away from the expected inundation areas to higher ground; shutting down of coastal power plants, which means blacking out its service area; evacuating sea ports and coastal infrastructure facilities such as desalination plants, oil and gas refineries, etc. From a state point of view, this is a massive operation that distract daily life activities on a national scale. This is of course well justified in case of a real alarm, yet the cost of a false alert can be tremendous.

The challenge is obvious: is there a real need to alert the country or not? True alarms are necessary and must not be missed, false alarms are forgivable if the public is well educated to live with them, yet missed alarms are not bearable. In order to make the alert efficient and avoid confusing the chain of operation and eventually the public, these issues should be elaborated between the scientific unit and the national decision makers ahead of time, and even in real time when needed [32].

\subsection{National Civil Protection Agencies and Disaster Management Offices}

The alerts distributed by the NDM should address, rapidly and simultaneously, all levels of recipients under threat within the national civil protection Agencies (CPAs) and disaster management offices (DMOs). Included are all kinds of national units, governmental offices, infrastructure facilities, local authorities, municipalities etc., with the aim of reaching all the relevant public at risk. This is the "last mile" of the alerting process, but it is not short at all.

The challenge of the CPAs and DMOs is to stand by $24 / 7$, while the repeat time of the tsunami hazard may last decades or even centuries. They must fully take responsibility to consider and perform all aspects needed for an emergency response beforehand [18], understand the content of the warning messages in real time and be able to distribute the alert down-stream to all people at risk. Clearly, the efficient conduct of the alerting process depends on proper planning and detailed preparations ahead of time, so that at the moment of truth, every person in need gets the warning, knows what to do and is able to save their life [37].

\subsection{The Public}

The general public, including all persons under threat and at risk, in any given place, moment and circumstances, is the end recipient of the alerting messages. The challenge to every person is not only to receive the message, but to fully understand its meaning, know what to do and how to survive. This is not simple at all, because proper conduct under life threatening circumstances depends on prior awareness and proper preparedness. Nonetheless, it is the responsibility of the national and district civil protection agencies, as well as the local authorities, to guide and prepare the public for such a catastrophe [37]. These issues are elaborated further in Section 7.1. 


\section{The Domains}

The great destruction caused by the May 1960 Chilean and March 1964 Alaskan Tsunamis around the Pacific emphasized the need for an International Tsunami Warning System [38], thus bringing the management of the initial stages of tsunami warning to the international sphere. As a result, the ETE architecture operates under three domains: regional, national and local.

The regional is the uppermost sphere in which the ICGs operate, and each of them involves a group of several nations that share the same tsunami-threatened basins [39]. The national domain operates under the regional one, and it consists of the relevant ICG member states. The local is the lowest domain; it operates under the national level, and could be of any kind of DMO, CPA, governmental or ministerial office; municipality or authority; or any other group of citizens, such as a "Tsunami Ready" community [37]. The local domain, which is the last unit of the ETE chain, is responsible for distributing the warning to whomever is under threat.

The need to cooperate and coordinate the transfer of warning messages from top to bottom across the three domains, including lifesaving operations, raises obvious and trivial difficulties to cope with, particularly technical means of communication, a common language and terminology, and even the need to bridge cultural gaps [40]. In order to achieve the efficient conduct of alerting, all three domains must recognize and be familiar with each other and coordinate the exchange of messages.

\section{Communication-The Key to the Successful Transmission of an Alert}

The warning messages must be transmitted across the ETE architectural chain, fast and efficiently, without losing their level of severity, urgency and certainty. This is not trivial at all, because one end reads and speaks a professional scientific language and the other end expects to receive a simple, layman's explanation and instruction. Furthermore, the standard TSP language is English, while the end recipients speak a national tongue, if not a specific, local dialect [40].

Thus, while communication is the bridge to transfer tsunami alerts, it poses potential barriers. The challenge, then, is to construct a common language and terminology, clear and understandable to both the sender and the receiver, built within a structure defined and accepted by the two sides ahead of time. The content of the sent messages must convey the necessary information required by the recipient. TSPs should rephrase scientific jargon into decision-makers terms, which in turn need to reshape it into clear instructions to civil protection agencies, which in turn have to distribute it to the public in a daily spoken language.

Overall, there are several preconditions for an efficient conduct and transfer of the warning messages along the ETE chain. Each element should be familiar with the architecture and standard of practice of its "neighbor"; agree and be familiar with the common language, terminology, structure and content of messages; and coordinate means of transmission and communication, including the simultaneous use of several channels (e.g., GTS, e-mail, SMS and facsimile) for backing up the alert. Eventually, the credibility of the system is no stronger than its weakest link.

Another obstacle is the poor ability of contemporary science and technology to forecast quantitatively the expected level of tsunami threat in real time, shortly after the earthquake. Empirical data and experience allow the construction of tsunami decision matrixes that are limited to distinguishing negligible, low and high levels of threat only [18], with a significant degree of uncertainty. The challenge is thus to rapidly, accurately and reliably distribute tsunami warning messages on the basis of preliminary data and large uncertainty, and still warn the public with a short, clear and simple message, such as "Tsunami alert, get away from the coast, go to high ground". 


\section{The Last Mile}

Distributing the official alert to the general public is the ultimate goal of the alerting process, because this is what drives lifesaving and damage-minimizing actions. The challenge is reaching every person at risk and making sure they know what to do and are able to do so [41].

\subsection{Reaching the Public}

In the case of far field tsunamis, where no natural signal of earthquake shaking is available, efficient alerting requires that all means of communication should be involved. The fastest and most efficient way to alert the public is to establish a national or regional public address (PA) system (of loudspeakers for example) that is controlled from a single operational center and distributes the alert within seconds of the NDM decision. Likewise, a direct alert to critical infrastructure and industry facilities can be disseminated from the same operation center. In parallel, and of no less importance as a relatively fast and effective course of action, the alert can be broadcast by bursting the media (radio and television) and dispersing it across social web networks. Farther along, CPAs (e.g., police and coast guards) and their personnel should target the alert to those within the zone of expected inundation by all available means, such as sirens and loudspeakers. A further advantage is that these professional forces are closely familiar with the alerted area and can react fast and effectively to any developing situation in real time. Even helicopters can be recruited by flying along the coastline and alerting vacationers on the beach and inside the sea. This is a slower way of action due to the long chain of command required to initiate the operation and the time needed to reach the threatened areas, but it is an effective way to reach remote and isolated places.

Near-field tsunamis impose automatic reaction and shortcut procedures in order to cope with the short arrival time to the coast, and this is again the responsibility of the CPAs and DMOs to educate and direct the public on how to conduct self-lifesaving actions.

\subsection{Saving Lives}

Successful ETE architecture and efficient data and messaging flow are not enough, because the people should know what to do, and if needed do it. The arrival of a tsunami alert to the end member recipients should trigger lifesaving actions, and the challenge is to drive the crowd to act properly as soon as the alert is accepted. It requires the public to trust the alerting system, understand the message, know what to do and just do it, even though at some point the alert can be canceled. The public should be informed and educated that the warning process improves as more information arrives and therefore be ready to accept a cancelation of the alert without losing trust in the system. The public should be taught how to react according to where they are during the event and trained in doing the right actions, which basically are self-saving acts.

The key to the successful completion of the lifesaving process is thus proper awareness and preparedness of the public ahead of time. This is further elaborated below.

\section{Beyond the Alert-Awareness and Preparedness}

Alerting a public that is not aware of the hazard and not prepared to take lifesaving actions is hopeless, and this is the role of awareness and preparedness. Thus, while the ETE architecture aims to convey the warning messages to the public in need, the end recipients must be attentive and ready to take action, otherwise the alert is wasted.

The essence of awareness is bringing both the authorities and the public to be familiar with the tsunami phenomenon; learn what its typical characteristics are and how to identify them; why it is a hazard and its possible consequences; be aware that it can really happenand where and when it can do so [42]. The challenge is to teach the civil authorities, coastal management bodies and the public to remain on standby for a long time and take all necessary actions at the right moment, even though it is a rare event and most of them have not experienced such an event before. 
Preparedness in the present context refers to actions necessary to prevent loss of life and minimize damages, and it includes all needed actions that enable a country to better overcome a devastating emergency event. Effective and suitable preparedness requires a good understanding of the specific socio-cultural context of the local community, and taking those into account when programing suitable activities needed to target all levels, from the governmental all the way down to every household at the community level [43]. The responsibility to realize preparedness should be authorized at the state level and directed from top CPAs and DMOs levels down to all national infrastructure, civilian authorities, private sectors and eventually the general public.

In fact, establishing and maintaining all the components of the ETE architecture within the national and local domains (as already described above) is the foremost and elementary stage of preparedness that a state should have. It demands a great deal of resources to organize and specific focus to implement, but an efficient alert can only be achieved when this suite of activities is coordinated and activated simultaneously at all levels and times.

Even environmental and urban planning, as well as formulating proper codes for making buildings resistant to tsunami impacts [44], and particularly locating and constructing vertical evacuation structures [45,46], should be considered integral parts of tsunami lifesaving preparedness activities. The key is in bringing to mind tsunami awareness at all levels from the beginning, including planners and engineers as pointed above, so as to avoid unfortunate actions, such as placing schools in zones vulnerable to tsunami inundation. The ultimate goal is making all different clients and recipients be familiar and capable of the right lifesaving and damage minimizing actions ahead of time and particularly at the right moment [40].

\subsection{Evacuation, Signage and Route Mapping}

Experience shows that the probability of surviving a $1 \mathrm{~m}$ tsunami inundation wave height is about $50 \%$ and above $2 \mathrm{~m}$ high it is hopeless [47]. This is the reason why evacuation far from or above the inundation zone is the most important lifesaving action. Nevertheless, it is the responsibility of the civil authorities to identify ahead of time the zones of expected inundation; plan and sign evacuation routes and assembly points in a safe zone; and educate and train the public in how to react if needed. Posting road signs of tsunami hazard symbols is the most common way to notify the public whether they are in a zone of expected inundation, and where to evacuate and assemble if a tsunami alert is triggered and effective lifesaving actions are needed. The tendency is to follow a common, international signage language recommended by ISO.org. [48], and so people become familiar with tsunami hazard signs, no matter where they are coming from and what language they speak. There are many examples of tsunami signage from around the world, such as those guided by the New Zealand Ministry of Civil Defense \& Emergency Management [49], or Indonesia, Chile, Japan, Hawaii (USA) and Washington (USA), as are presented at itic.ioc-unesco.org [50]. Figure 2 illustrates tsunami signage recently posted along the Mediterranean coast of Israel, including the signs that indicate the entrance to a tsunami hazard zone (Figure 2a), the fastest and safest escape route and distance to the assembly zone (Figure 2b) and the location of the assembly zone (Figure 2c).

Much effort is invested in developing innovative portal and cellphone apps in order to ensure a proper response and enhance traditional evacuation drills of the public [51] or allow the public to learn their evacuation route ahead of time [52]. CWarn [53], for example, a not-for-profit humanitarian initiative website, allows its members to register for a free tsunami warning wherever they are around the world by SMS text message on their mobile phones. As much as such initiatives are highly acknowledged, it is the sole responsibility of any sovereign country to provide each of its citizens professional, reliable and timely $24 / 7$ tsunami early warning. 


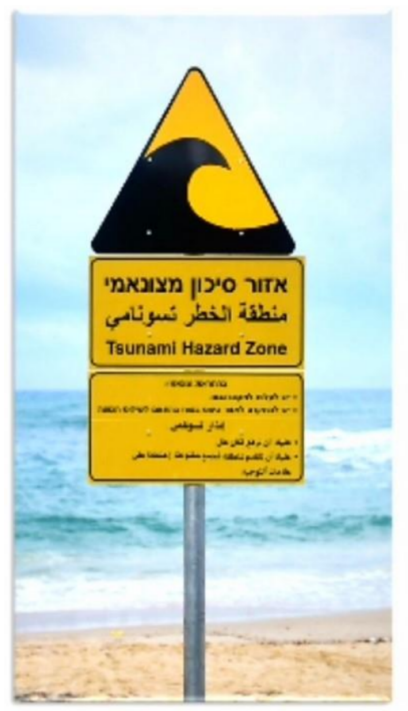

(a)

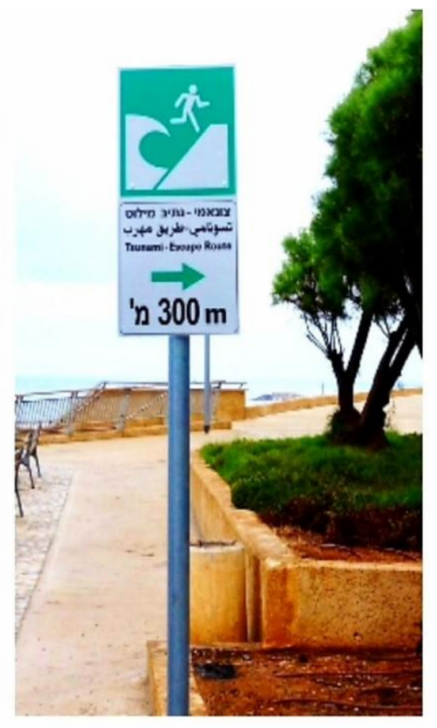

(b)

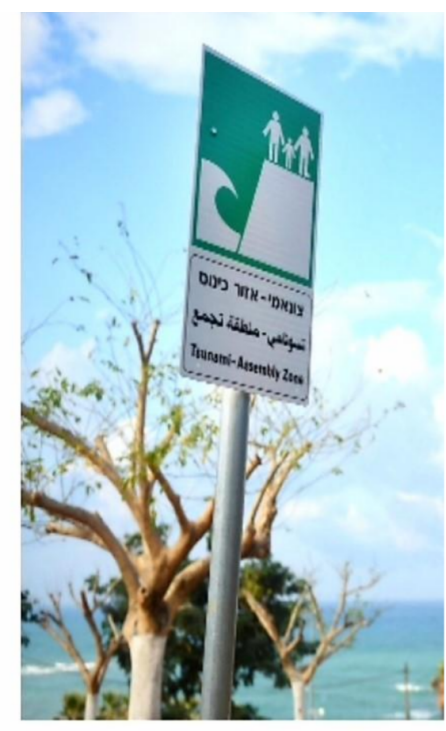

(c)

Figure 2. Tsunami hazard road signs installed along the Mediterranean coast of Tel-Aviv, Israel: (a) hazard zone; (b) escape route and distance to the assembly zone; and (c) assembly point. Photographs by A.Y., Tel Aviv, 2016.

To increase the effect and visibility of the signage system, the Israeli National Steering Committee for Earthquake Preparedness is developing a location map that shows each and every hazard, escape and assembly sign. The maps will be shared with all the local authorities; emergency and rescue forces; and the public, and assist the emergency forces in reaching more directly and faster the public in need, save crucial time and improve lifesaving actions [54].

The map symbology reflects the exact location of every single sign and its purpose. For example, a red flag denotes a tsunami hazard zone (Figure 3a), a yellow flag denotes an escape route (Figure 3b), and a green flag indicates an assembly zone (Figure 3c). This way the public will get a comprehensive view and better understanding of the entire emergency plan.

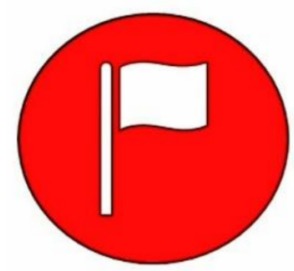

(a)

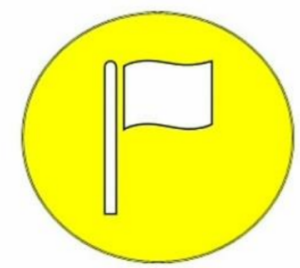

(b)

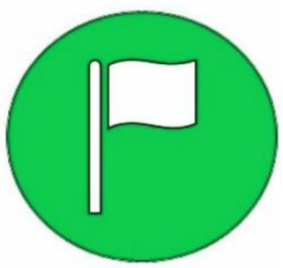

(c)

Figure 3. Flag symbols of the tsunami road signs used for the self-evacuation map: (a) red for the hazard zone; (b) yellow for evacuation routes; and (c) green for assembly points (see also Figure 4). Signage symbols by Dr. Orna Ido-Lichtman, Israel's National Steering Committee for Earthquake Preparedness.

Better yet is to upload the maps on an interactive cellphone application (under development) and allow every person in need to identify in real time their present position in regard to the expected inundation area [55]. Furthermore, such an app can allow one to find one's way to the closest assembly zone along a signed and safe route, as is being developed today in Israel (Figure $4 a, b)$. 


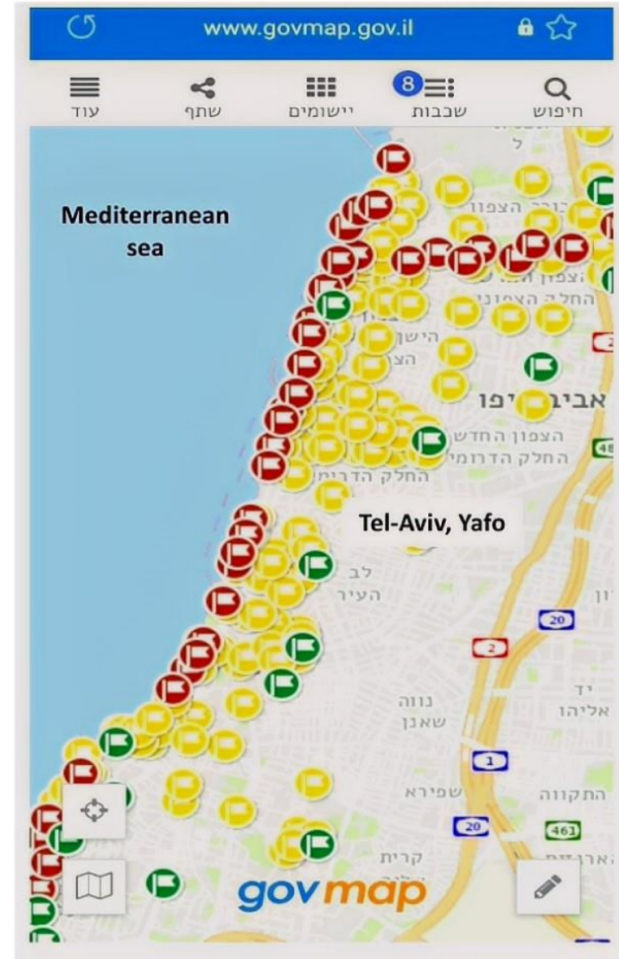

(a)

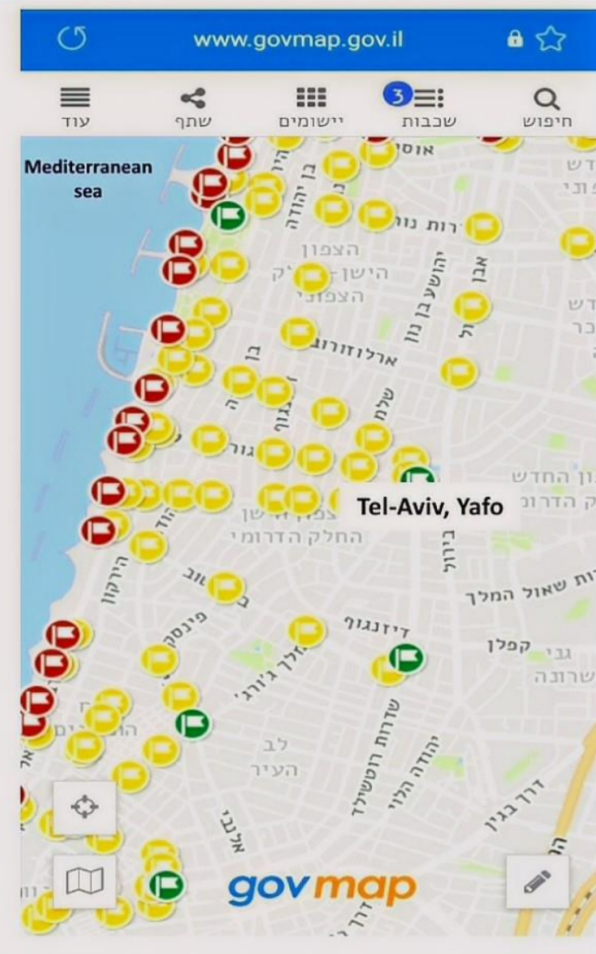

(b)

Figure 4. Tsunami signage self-evacuation map of: (a) greater Tel Aviv; (b) central Tel Aviv. Color flag symbols denote the location of the tsunami road signs as follows: red for a hazard zone, yellow for evacuation routes and green for assembly points (see also Figure 3). Background map by the Survey of Israel, https: / / www.govmap.gov.il (accessed on 25 January 2022); signage of self-evacuation plan by the author A. Y.; and courtesy of Dr. Orna Ido-Lichtman and Mr. Daniel Lanza, Israel's National Steering Committee for Earthquake Preparedness.

\subsection{Educate, Train and Drill}

The time between tsunami events can last years, and tsunami preparedness can be perceived as a waste of time and resources. However, there are no shortcuts: "If you think education is expensive, try ignorance", especially because the potential unbearable cost of tsunami casualties is avoidable by very simple measures- "go away and high from the inundation zone".

The best way, though not necessarily the only one, to convey this notion is education [42]. The formal, national education system is the most efficient alternative, because young kindergarten and school children can bring home to their parents what they have learned at school, carry this knowledge with them through their lives and tell their children the story. Nonetheless, sustaining public education over generations remains one of the biggest challenges, but it is also arguably a keystone activity for saving lives from tsunamis [14].

Training is an integral part of learning, especially in lifesaving actions, without which the acquired knowledge and understanding fades away. The need is to exercise routinely the whole process by both the authorities who are in charge of the practice and the public, and particularly drill the actual evacuation and walking along the escape routes to the assembly zones [56].

\subsection{Care of the Disabled-No One Is Left Behind}

Often there is not enough time left for evacuation before the tsunami arrives, especially for slow moving and disabled people. Therefore, evacuation planning, education and 
training must consider solutions for those who cannot practice self-saving actions alone [57]. For example, mutual assistance should be an integral part of the practice, taken as the duty of young students. Other creative solutions such as vertical evacuation are needed as well.

\section{Not All Tsunamis Are Generated Equal}

While planning the tsunami emergency response, one should bear in mind that tsunamis are different from each other and much flexibility is required to cope with future scenarios. It is not only the unexpected timing and magnitude of the event, but also the source and mechanism that may surprise and catch us "not prepared".

The most significant difference is between tsunamis coming from a far distance-in which case the warning may arrive by telecommunication and there can be some time to react-and local tsunamis in which the earthquake shaking or abnormal behavior of the sea are the only warning signals and immediate evacuation is necessary. Awareness and preparedness need to consider both scenarios [58]. Yet further complexities should be expected, because all types of earthquakes can generate submarine and/or subaerial tsunamigenic landslides-even on-land earthquakes near the coast [59,60]. Furthermore, the common notion is that thrust mechanism earthquakes, mostly along subduction zones, pose the main threat and thus strike-slip events may appear as a "surprise" [61-63]; tsunamigenic volcanoes also go underrated [64], and so on. What remain unexpected indeed, and so far lack preceding signals, are spontaneous tsunamigenic submarine and subaerial landslides. Real time sea-level monitoring systems can bridge this gap.

The challenge is thus this: while there are numerous plausible tsunami scenarios that ETE architecture needs to be aware of and prepare for, the public should get clear and simple instructions on how to cope with this natural hazard, regardless of its generating mechanism.

\section{A Case Study of a Decision-Making Dilemma}

Real events present numerous dilemmas to coping with and arriving at a practical, fast and efficient solution. Behrens [33] proposed how to handle the problematics of the inherent uncertainties and differences that arise in real time from TSP warning messages. A classic example is the tsunami warning messages issued by the already accredited NEAMTWS TSPs regarding the 25 October 2018, $16.8 \mathrm{~km}$ depth, mb 6.3, MS 6.9 [65] tsunamigenic earthquake (Figure 5) in the Mediterranean Sea southwest of Greece. Israel, a NEAMTWS member state, received at that time two different, legitimate tsunami-warning messages. The first one arrived from the INGV (Italy TSP) at 23:02, sending Israel a "Tsunami Information" (Figure 6a). The second message, arriving from NOA (Greece TSP) one minute later, notified a "Tsunami Advisory" level of alert to Israel (Figure 6b). The analyses, the best practice of the two TSPs, were regarded reliable, and the differences may have originated from the SOPs and mathematical and decision modules each TSP was using. 


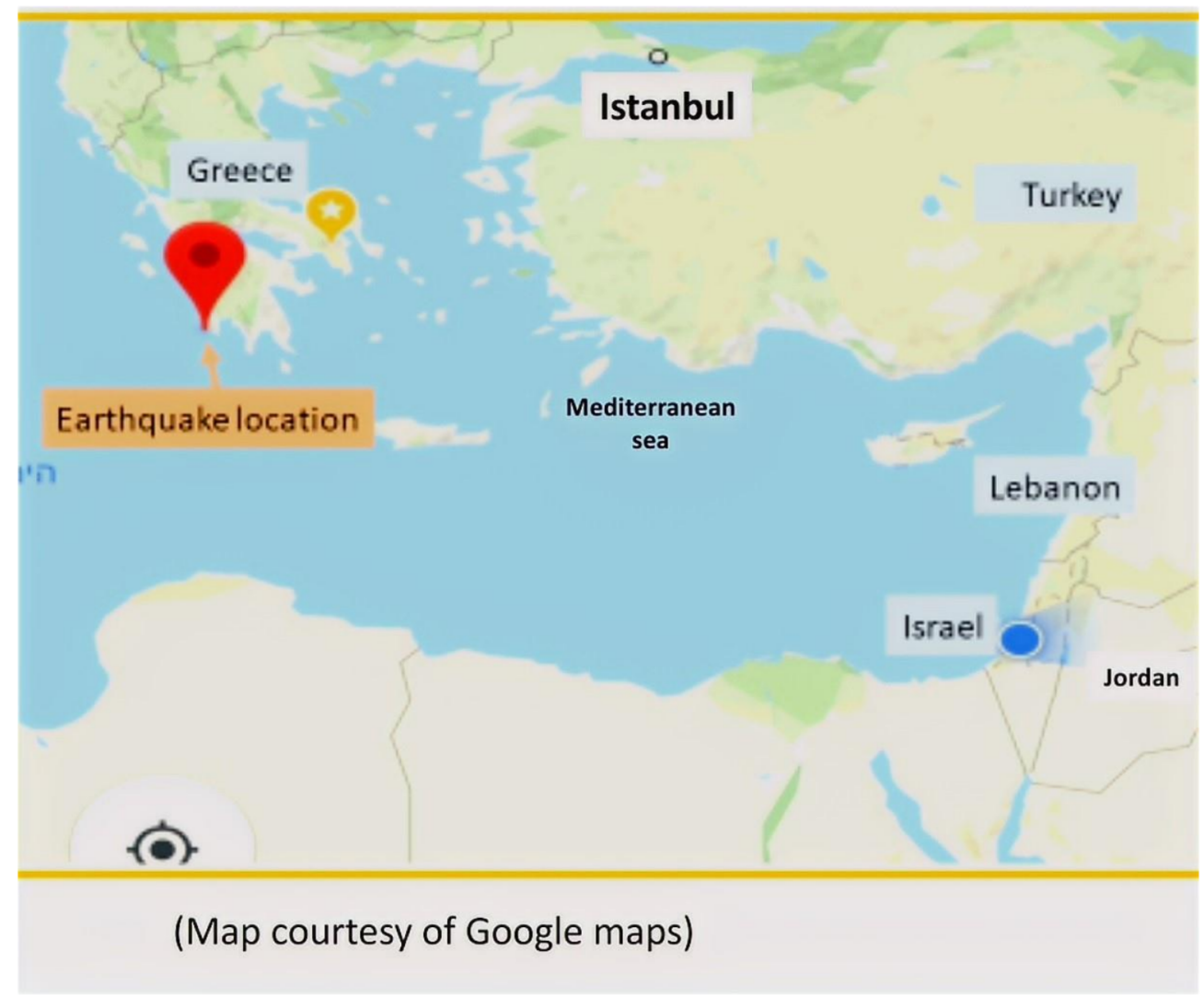

Figure 5. Location map of the 25 October 2018 earthquake south west of Greece. Origin time 22:54:51.80, lat. 37.47, long. 20.72, depth $16.8 \mathrm{~km}$, mb 6.3, MS $6.9[65,66]$.

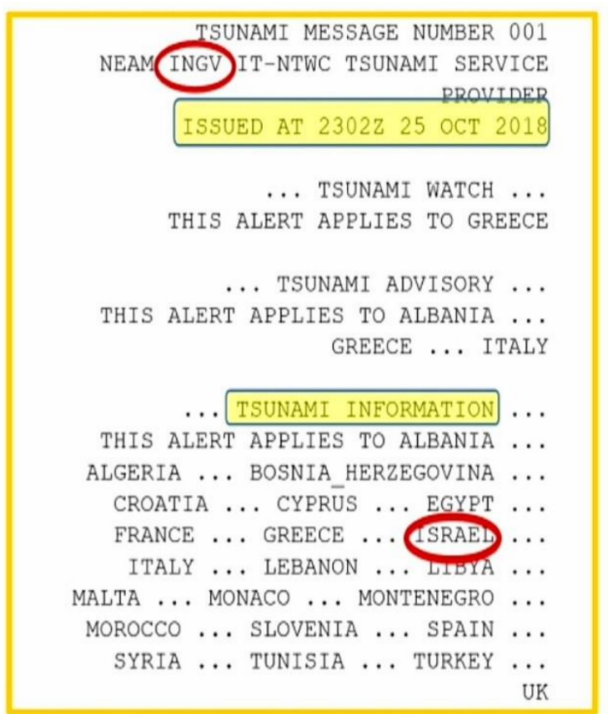

(a)
Subject: TSUNAMI MESSAGE NUMBER 001

TSUNAMI MESSAGE NUMBER 001

NEAN NOA HL-NTWC TSUNAMI SERVICE

PROVIDER

ISSUED AT $2303 Z 25$ OCT 2018

... TSUNAMI WATCH ...

THIS ALERT APPLIES TO GREECE...ITALY

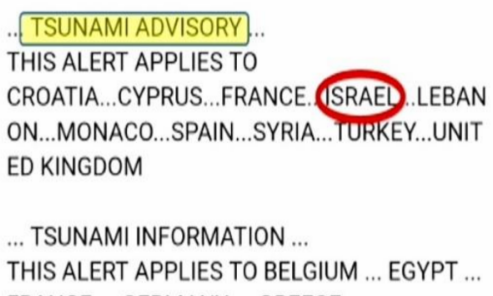

... TSUNAMI INFORMATION ...

THIS ALERT APPLIES TO BELGIUM ... EGYPT ... FRANCE ... GERMANY ... GREECE

(b)

Figure 6. Tsunami alert messages received in Israel regarding the 25 October 2018 earthquake southwest of Greece: (a) INGV message issued on 23:02 "Tsunami Information" to Israel; (b) NOA message issued on 23:03 "Tsunami Advisory" to Israel.

From Israel's stand point, the near real time source parameters determined by the two TSPs indicated a "Tsunami Advisory" on the basis of the decision matrix recommended for use in Israel [67]. However, as further information regarding sea level measurements in Crete and Cyprus arrived with no indication of clear abnormal behavior, the Israel 
NDM (named "Migdalor" in Hebrew) consulted its NTWC (named "Nachshol Nitzpeh" in Hebrew) and concluded a "Tsunami Information" only, and no official alert was issued.

\section{Concluding Words}

\subsection{Comprehensive and Flexible End-to-End Architecture}

The leading concept behind efficient tsunami alerting is lifesaving. It requires the good conduct of transmitting the warning from one end-the detection of a potential tsunamigenic earthquake-to the other end-the people at threat. Yet without proper awareness and preparedness, the alert may just confuse the public and disorient rescue actions. The current NEAMTWS ETE architecture [18] presents a sound management of the alerting process. Here we proposed complementing this data and messaging flow by optional shortcuts and reinforcing the alerting process with appropriate awareness and preparedness (Figure 7).

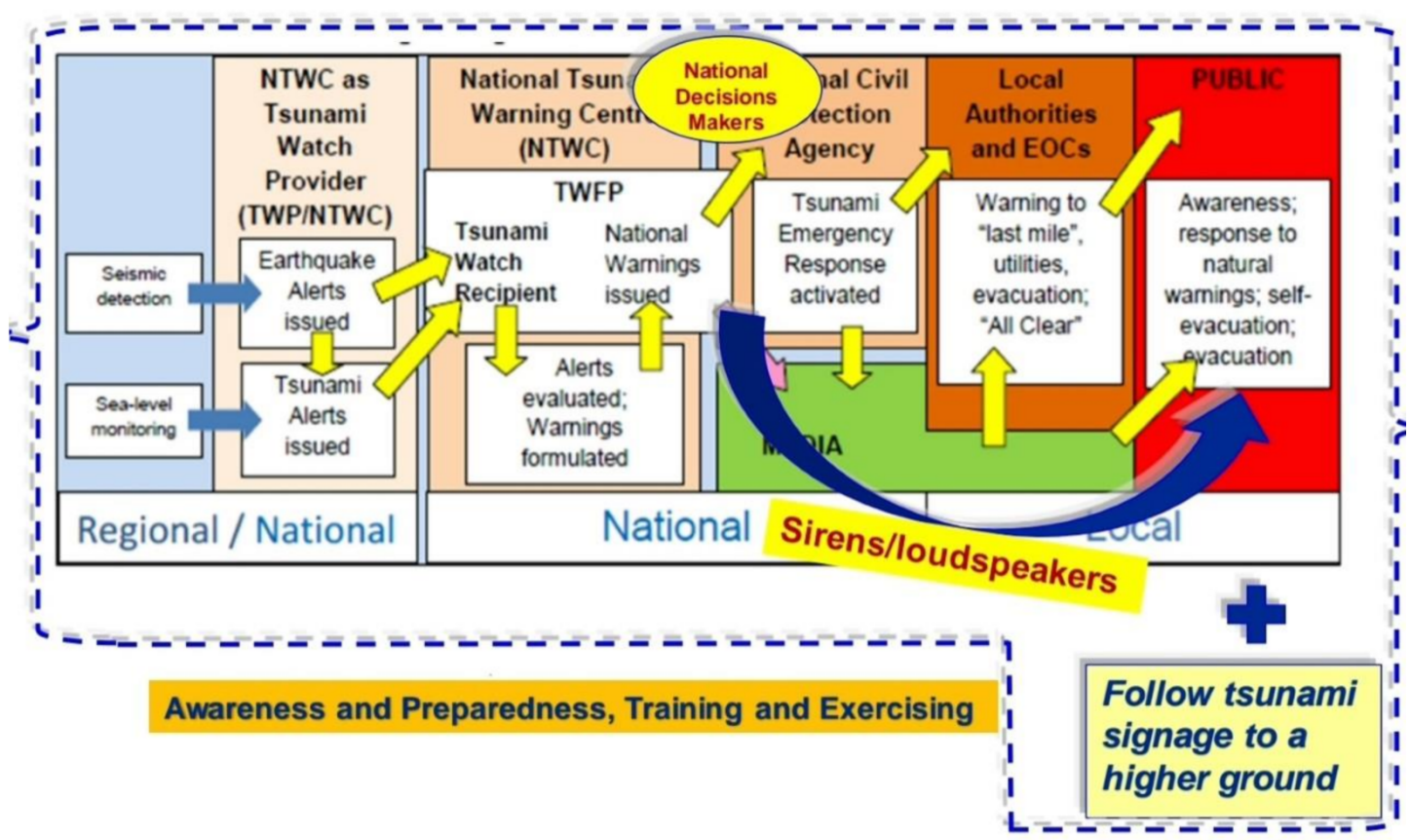

Figure 7. Suggested modifications to the NEAMTWS end-to-end alerting architecture [18]. The focus is on adding national decision makers (NDM) components and complementary shortcuts that allow more direct and faster flows of messaging from the NDM to the public in case it is clear that a tsunami was generated and arrival time is short. In addition, there is a need to emphasize tsunami awareness and preparedness across all the participating units.

A trivial yet crucial shortcut is a must if a significant tsunami is generated and the arrival time is short. In such events, NDMs must alert and activate the public directly, while in parallel roll the alerting commands along the formal chain of responsible authorities, and thus save precious time. Similarly, an NTWC can alert simultaneously both the NDM and the local authorities. Clearly, these actions should be formulated and agreed in advance by all participating units.

Nonetheless, even an efficient and fast flow of messages would be ineffective if the public is not tsunami ready. The alerting process must be supported by proper education and training, complemented by the delineation of inundation zones and evacuation routes, so as that in the moment of truth people under threat will indeed receive the alert and save their lives [68]. 


\subsection{The Alerting Chain Is as Strong as Its Weakest Unit}

Much has been published on orderly SOPs; manuals; and user guides on how to manage tsunami warnings, awareness and preparedness, and many such examples were mentioned in this entry. Altogether and above the technicalities, the alerting procedure seeks flexibility in coping with unexpected scenarios and the efficient conduct of lifesaving as its ultimate goal.

Beyond the formalities, alerting would be as effective as its most incompetent unit, the flow of warning messages would be as fast as its slowest segment, the ETE architecture would be as efficient as its most inexpert component and thus the alerting chain would be as strong as its weakest unit.

Author Contributions: Both authors, A.Y. and A.S., contributed equally and shared conceptualization, writing and editing of the text. All authors have read and agreed to the published version of the manuscript.

Funding: This research received no external funding.

Acknowledgments: We thank Orna Ido-Lichtman and Daniel Lanza, Israel's National Steering Committee for Earthquake Preparedness, for their assistance in planning the self-evacuation map. We highly appreciate the four anonymous reviewers for their critical readings of the manuscript and constructive comments.

Conflicts of Interest: The authors declare no conflict of interest.

Entry Link on the Encyclopedia Platform: https:/ / encyclopedia.pub/20356.

\section{References}

1. Behrens, J.; Løvholt, F.; Jalayer, F.; Lorito, S.; Salgado-Gálvez, M.A.; Sørensen, M.; Abadie, S.; Aguirre-Ayerbe, I.; Aniel-Quiroga, I.; Babeyko, A.; et al. Probabilistic Tsunami Hazard and Risk Analysis: A Review of Research Gaps. Front. Earth Sci. 2021, 9, 628772. [CrossRef]

2. Lorito, S.; Behrens, J.; Løvholt, F.; Rossetto, T.; Selva, J. Editorial: From Tsunami Science to Hazard and Risk Assessment: Methods and Models. Front. Earth Sci. 2021, 9, 764922. [CrossRef]

3. Okal, E.A. Twenty-Five Years of Progress in the Science of "Geological" Tsunamis Following the 1992 Nicaragua and Flores Events. Pure Appl. Geophys. 2019, 176, 2771-2793. [CrossRef]

4. Marris, E. Inadequate warning system left Asia at the mercy of tsunami. Nature 2005, 433, 3-5. [CrossRef] [PubMed]

5. Okal, E.A. The Quest for Wisdom: Lessons from 17 Tsunamis, 2004-2014. Phil. Trans. R. Soc. A 2015, 373, 20140370. [CrossRef] [PubMed]

6. Uchida, N.; Bürgmann, R. A decade of lessons learned from the 2011 Tohoku-Oki earthquake. Rev. Geophys. 2021, 59, e2020RG000713. [CrossRef]

7. WCDRR (World Conference on Disaster Risk Reduction). The Sendai Framework for Disaster Risk Reduction 2015-2030. In Proceedings of the Third United Nations World Conference on Disaster Risk Reduction, Sendai, Miyagi, Japan, 14-18 March 2015. Available online: https:/ / www.preventionweb.net/files/43291_sendaiframeworkfordrren.pdf (accessed on 25 January 2022).

8. WCDRR (World Conference on Disaster Risk Reduction). The Sendai Declaration. In Proceedings of the Third United Nations World Conference on Disaster Risk Reduction, Sendai, Miyagi, Japan, 14-18 March 2015. Available online: https://www. preventionweb.net/files/43300_sendaideclaration.pdf (accessed on 25 January 2022).

9. UNESCO/IOC (Intergovernmental Oceanographic Commission of UNESCO). Tsunami Risk Assessment and Mitigation for the Indian Ocean; Knowing Your Tsunami Risk-and What to Do About It. IOC Manuals and Guides No. 52, 2nd ed.; UNESCO: Paris, France, 2015. (In English)

10. North-Eastern Atlantic, Mediterranean and connected seas Tsunami Information Centre. NEAMTIC-Home. Available online: http:/ / neamtic.ioc-unesco.org/ (accessed on 25 October 2021).

11. ICO. Proceedings of the Eleventh Session of the Intergovernmental Coordination Group for the Tsunami and Other Coastal Hazards Warning System for the Caribbean and Adjacent Regions, Cartagena de Indias, Colombia, 5-7 April 2016. Available online: http://www.ioc-tsunami.org/index.php?option=com_oe\&task=viewEventRecord\&eventID=1784 (accessed on 25 January 2022).

12. Tsunami Warning Centers. Available online: https://tsunami.gov/ (accessed on 24 October 2021).

13. Japan Meteorological Agency. Available online: https://www.jma.go.jp/jma/indexe.html (accessed on 24 October 2021).

14. Kong, L.S.L.; Paula, K.; Dunbar, A.N. (Eds.) Pacific Tsunami Warning System: A Half Century of Protecting the Pacific, 1965-2015; International Tsunami Information Center: Honolulu, HI, USA, 2015.

15. PTM (Pacific Tsunami Museum). Available online: http://tsunami.org/the-warning-system/ (accessed on 24 December 2021).

16. ICG/NEAMTWS-VIII. Interim Operational Users Guide for the Tsunami Early Warning and Mitigation System in the North-eastern Atlantic, the Mediterranean and Connected Seas (NEAMTWS); Version 2.00; ICG/NEAMTWS-VIII: Rome, Italy, 2011. 
17. Papadopoulos, G.; Lekkas, E.; Katsetsiadou, K.-N.; Rovithakis, E.; Yahav, A. Tsunami Alert Efficiency in the Eastern Mediterranean Sea: The 2 May 2020 Earthquake (Mw6.6) and Near-Field Tsunami South of Crete (Greece). GeoHazards 2020, 1, 44-60. [CrossRef]

18. UNESCO/IOC (Intergovernmental Oceanographic Commission of UNESCO). In Reducing and Managing the Risk of Tsunamis; IOC Manuals and Guides; United Nations Educational, Scientific and Cultural Organization: Paris, France, 2011 ; Volume 57.

19. Fukuji, T. ITIC Tsunami Awareness and Education Materials-International Tsunami Information Center. 2021. Available online: http: / /itic.ioc-unesco.org/index.php?option=com_content\&view=article\&id=1349\&Itemid=+1075\&lang=en (accessed on 25 October 2021).

20. NWS JetStream-Tsunami Preparedness and Mitigation: Individuals (You!). Available online: https://www.weather.gov/ jetstream/prep_you (accessed on 25 October 2021).

21. UNESCO/IOC (Intergovernmental Oceanographic Commission of UNESCO). Users Guide for the Pacific Tsunami Warning Center Enhanced Products for the Pacific Tsunami Warning System. In IOC Technical Series No 105; Revised edition; 2014. Available online: http:/ /itic.ioc-unesco.org/images/stories/about_warnings/what_are_they/ts105-Rev2_eo_220368E.pdf (accessed on 25 January 2022).

22. UNESCO/IOC (Intergovernmental Oceanographic Commission of UNESCO). Available online: http://www.ioc-tsunami.org/ (accessed on 26 December 2021).

23. UNESCO/IOC (Intergovernmental Oceanographic Commission of UNESCO). Tsunami Service Providers (TSPs). Available online: https:/ / ioc.unesco.org/our-work/global-tsunami-early-warning-and-mitigation-programme (accessed on 24 December 2021).

24. IOC (Intergovernmental Oceanographic Commission of UNESCO). Plans and Procedures for Tsunami Warning and Emergency Management; IOC Manuals and Guides; United Nations Educational, Scientific and Cultural Organization: Paris, France, 2017; Volume 76, p. 72.

25. Michaels, M. Buoy Data and Tsunami Preparedness; WeatherNation: Centennial, CO, USA, 2021. Available online: https://www. weathernationtv.com/news/buoy-data-and-tsunami-preparedness/ (accessed on 26 October 2021).

26. Mulia, I.E.; Satake, K. Developments of Tsunami Observing Systems in Japan. Front. Earth Sci. 2020, 8, 145. [CrossRef]

27. Annunziato, A. The inexpensive device for sea level measurements. Sci. Tsunami Hazards J. Tsunami Soc. Int. 2015, 34, 199-211. Available online: https:/ / webcritech.jrc.ec.europa.eu/TAD_server/Data/Documents/IDSL\%20Description.pdf (accessed on 25 January 2022).

28. European Comission. TAD Server. Available online: https://webcritech.jrc.ec.europa.eu/TAD_server/Home (accessed on 26 October 2021).

29. Lipa, B.; Barrick, D.; Isaacson, J. Evaluating HF Coastal Radar Site Performance for Tsunami Warning. Remote Sens. 2019, 11, 2773. [CrossRef]

30. Amato, A. Some reflections on tsunami Early Warning Systems and their impact, with a look at the NEAMTWS. Bollettino di Geofisica Teorica ed Applicata 2020, 61, 403-420. [CrossRef]

31. Necmioğlu, Ö.; Turhan, F.; Özer Sözdinler, C.; Yılmazer, M.; Güneş, Y.; Cambaz, M.D.; Altuncu Poyraz, S.; Ergün, T.; Kalafat, D.; Özener, H. KOERI's Tsunami Warning System in the Eastern Mediterranean and Its Connected Seas: A Decade of Achievements and Challenges. Appl. Sci. 2021, 11, 11247. [CrossRef]

32. Salamon, A.; Rosen, D.S.; Gitterman, Y.; Yahav, A.; Ben-Arieh, S.; Debutton, Y.; Dover, D.; Vatenmacher, M.; Miloh, T. Recommendations on the Policy, Warning Principles and Frame of Preparedness for Tsunamis in Israel. The Scientific Committee for Formulating Policy of Early Warning Principles for Tsunami Hazards in Israel; Geological Survey of Israel Report GSI/16/2014; Geophysical Institute of Israel, Report 30/797/14; Israel Oceanographic and Limnological Research, Report H36/2014 (In Hebrew, English Abstract). 2014. Available online: https:/ / www.gov.il/BlobFolder/reports/salamon-et-al-report-2014-16/he/report_20 14_Salamon-Amos-Policy-Principles-Preparedness-Tsunamies-Israel-GSI-16-2014-GII-030-797-14-H36-2014.pdf (accessed on 25 January 2022).

33. Behrens, J. How to Handle Diverging TSP Warning Messages and Know about the Inherent Uncertainty. In Proceedings of the 14th Session of ICG/NEAMTWS, Lisbon, Portugal, 21-23 November 2017. Available online: http://legacy.iocunesco.org/index. php?option=com_oe\&task=viewDocumentRecord\&docID=20623 (accessed on 25 January 2022).

34. Selva, J.; Lorito, S.; Volpe, M.; Romano, F.; Tonini, R.; Perfetti, P.; Bernardi, F.; Taroni, M.; Scala, A.; Babeyko, A.; et al. Probabilistic tsunami forecasting for early warning. Nat. Commun. 2021, 12, 5677. [CrossRef] [PubMed]

35. Shepardson, D. FCC Says Appears Hawaii Had No Safeguard to Stop Missile Scare. Reuters. 14 January 2018. Available online: https:/ / www.reuters.com/article/usa-missiles-falsealarm-fcc-idINKBN1F30TP (accessed on 25 January 2022).

36. Samarajiva, S.; Gunawardene, N. Crying Wolf Over Disasters Undermines Future Warnings. Available online: https://www. scidev.net/global/opinions/crying-wolf-over-disasters-undermines-future-warnings/ (accessed on 25 January 2022).

37. IOC Tsunami Ready-International Tsunami Information Center. Available online: http://itic.ioc-unesco.org/index.php?option= com_content\&view =category\&id=2234\&Itemid=2758 (accessed on 24 October 2021).

38. Pararas-Carayannis, G. Tsunami Warning System in the Pacific: An Example of International Cooperation. In Natural and Man-Made Hazards; El-Sabh, M.I., Murty, T.S., Eds.; Springer: Dordrecht, The Netherlands, 1988. [CrossRef]

39. Intergovernmental-International Tsunami Information Center. Available online: http://itic.ioc-unesco.org/index.php?option= com_content\&view=category\&layout=blog\&id=2002\&Itemid=2002 (accessed on 26 October 2021). 
40. Tsunami Kit-Developing Early Warning and Community Preparedness in Indonesia. Available online: https://www.gitews.org/ tsunami-kit/index_en.html (accessed on 26 October 2021).

41. GITEWS: “Last Mile”. Available online: https://www.gitews.org/en/capacity-building/last-mile/ (accessed on 26 October 2021).

42. Fukuji, T. TsunamiTeacher (International)-International Tsunami Information Center. 2021. Available online: http://itic.iocunesco.org /index.php?option=com_content\&view=article\&id=1441:tsunamiteacher-international\&catid=2102\&Itemid=2420 (accessed on 27 October 2021).

43. Kong, L. Guarding against Tsunamis: The Challenge of Building Preparedness at the National and Local Levels. In Liaison; 2006. Available online: https://nctr.pmel.noaa.gov/education/ITTI/usgs/seismic-tsunami-training-maldives/tsunami_ preparedness_COE122905_3.pdf (accessed on 25 January 2022).

44. Chock, G. Design for tsunami loads and effects in the ASCE 7-16 standard. J. Struct. Eng. 2016, 142, 04016093. [CrossRef]

45. FEMA. Guidelines for Design of Structures for Vertical. Evacuation from Tsunamis. Available online: http:/ /www.fema.gov/ media-library-data/20130726-1641-20490-9063/femap646.pdf (accessed on 25 January 2022).

46. FEMA. Vertical Evacuation from Tsunamis: A Guide for Community Officials. Available online: https://damfailures.org/wpcontent/uploads/2019/12/fema_p646a.pdf (accessed on 25 January 2022).

47. FEMA. Hazus Tsunami Model User Guidance. Available online: https://www.fema.gov/media-library-data/1511284000292-4f1 8206fb0c7bab3c5ecbbbdf504b9fd/Hazus_40_Tsunami_User_Manual.pdf (accessed on 25 January 2022).

48. ISO. Available online: https://www.iso.org/obp/ui\#tiso:grs:7010:W056 (accessed on 26 October 2021).

49. New Zealand Ministry of Civil Defence \& Emergency Management. National Tsunami Signage Technical Standard for the CDEM Sector [TS 01/08]; Ministry of Civil Defence \& Emergency Management: Wellington, New Zealand, 2008; ISBN 0-478-25480-6.

50. Signs \& Symbols. Available online: http://itic.ioc-unesco.org/index.php?option=com_content\&view=category\&id=1406 \&Itemid $=2280$ (accessed on 25 December 2021).

51. Leelawat, N.; Suppasri, A.; Latcharote, P.; Abe, Y.; Sugiyasu, K.; Imamura, F. Tsunami evacuation experiment using a mobile application: A design science approach. Int. J. Disaster Risk Reduct. 2018, 29, 63-72. [CrossRef]

52. NVS Tsunami Evacuation Zones. Available online: http://nvs.nanoos.org/TsunamiEvac (accessed on 25 December 2021).

53. CWarn Tsunami Early Warning System. Available online: https:/ / cwarn.org/ (accessed on 8 January 2022).

54. UNESCO/IOC (Intergovernmental Oceanographic Commission of UNESCO); ICG/PTWS Working Group 3 (Awareness and Response). Defining Tsunami Hazard Areas: Concepts for Tsunami Evacuation Planning and Hazard Mapping. 2012. Available online: http:/ / www.ioc-tsunami.org/index.php?option=com_oe\&task=viewDocumentRecord\&docID=12617 (accessed on 25 January 2022).

55. NVS Tsunami Evacuation, NANOOS. Available online: https://apps.apple.com/us/app/nvs-tsunami-evacuation/id478984841 (accessed on 25 January 2022).

56. UNDP (United Nations Development Programme). Feel. See. Hear. Run. Don't Panic This Is Not Real, It's Just a Drill. Available online: https:/ / feature.undp.org/lessons-for-life/ (accessed on 26 December 2021).

57. Scheer, S.; Gardi, A.; Guillande, R.; Eftichidis, G.; Varela, V.; de Vanssay, B.; Colbeau-Justin, L. Handbook of Tsunami Evacuation Planning, SCHEMA (Scenarios for Hazard-Induced Emergencies Management), Project $n^{\circ}$, 030963; Publications Office of the European Union: Ispra, Italy, 2011.

58. American Red Cross. Tsunami Preparedness, Learn How, Why and Where to Evacuate if Conditions Suggest a Tsunami Risk in Your Area. 2021. Available online: https:/ / www.redcross.org/get-help/how-to-prepare-for-emergencies/types-of-emergencies / tsunami.html (accessed on 24 December 2021).

59. Salamon, A.; Di Manna, P. Empirical constraints on magnitude-distance relationships for seismically induced submarine tsunamigenic landslides. Earth-Sci. Rev. 2019, 191, 66-92. [CrossRef]

60. Synolakis, C.E.; Bardet, J.-P.; Borrero, J.C.; Davies, H.L.; Okal, E.A.; Silver, E.A.; Sweet, S.; Tappin, D. The slump origin of the 1998 Papua New Guinea tsunami. Proc. R. Soc. Lond. Ser. A 2002, 458, 763-789. [CrossRef]

61. Frucht, E.; Salamon, A.; Gal, E.; Ginat, H.; Grigorovitch, M.; Shem Tov, R.; Ward, S. A Fresh View of the Tsunami Generated by the Dead Sea Transform, 1995 Mw 7.2 Nuweiba Earthquake, along the Gulf of Elat-Aqaba. Seism. Res. Lett. 2019, 90, 1483-1493. [CrossRef]

62. Goda, K.; Mori, N.; Yasuda, T.; Prasetyo, A.; Muhammad, A.; Tsujio, D. Cascading geological hazards and risks of the 2018 Sulawesi Indonesia earthquake and sensitivity analysis of tsunami inundation simulations. Front. Earth Sci. 2019, 7, 261. [CrossRef]

63. Salamon, A.; Frucht, E.; Ward, S.N.; Gal, E.; Grigorovitch, M.; Shem-Tov, R.; Calvo, R.; Ginat, H. Tsunami Hazard Evaluation for the Head of the Gulf of Elat-Aqaba, Northeastern Red Sea. Front. Earth Sci. 2021, 8, 602462. [CrossRef]

64. Alter, T.R.; Haghighi, M.H.; Schneider, F.M.; Coppola, D.; Motagh, M.; Saul, J.; Babeyko, A.; Dahm, T.; Troll, V.R.; Tilmann, F.; et al. Complex hazard cascade culminating in the Anak Krakatau sector collapse. Nat. Commun. 2019, 10, 4339. [CrossRef] [PubMed]

65. ISC (International Seismological Centre). Available online: http://www.isc.ac.uk/iscbulletin/search/ (accessed on 24 December 2021).

66. Google Maps (2022) Map data@2022 Mapa GISrael, Scale:1:200. Available online: https://www.google.com/maps/@34.6433073, 29.3987385,5.83z (accessed on 25 January 2022). 
67. Salamon, A. Potential tsunamigenic sources in the eastern Mediterranean and a decision matrix for a tsunami early warning system. In Marine Geo-Hazards in the Mediterranean; Briand, F., Ed.; CIESM Workshop Monograph; CIESM: Monaco, 2011; Volume 42, pp. 35-42. Available online: http:/ / www.ciesm.org/online/monographs/Nicosia.html (accessed on 25 January 2022).

68. Get Tsunami Ready. Available online: https://www.civildefence.govt.nz/get-ready/get-tsunami-ready/ (accessed on 25 January 2022). 